\title{
$\mathrm{La}_{2}-{ }_{x} \mathrm{Sr}_{x} \mathrm{CuO}_{4}$ の過㮃ドープ領域における超伝導と 動的反強磁性磁気相関の消隇
}

脇本 秀一

（日本原子力研究開発機構 量子ビーム応用研究部門）

\section{Disappearance of Superconductivity and Dynamic Antiferromagnetic Correlations in Overdoped $\mathrm{La}_{2}-{ }_{x} \mathrm{Sr}_{x} \mathrm{CuO}_{4}$}

Shuichi Wakimoto

(Quantum Beam Science Directorate, Japan Atomic Energy Agency)

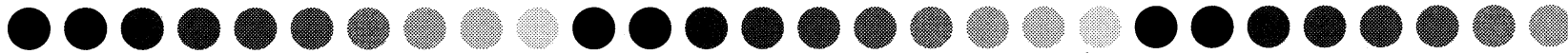

\begin{abstract}
Neutron scattering experiments have been performed to study spin excitations in the overdoped $\mathrm{La}_{2}-{ }_{x} \mathrm{Sr}_{x} \mathrm{CuO}_{4}(0.25 \leq x \leq 0.30)$ using triple-axis and time-of-flight techniques. Low energy magnetic excitations $(\omega<10 \mathrm{meV})$ show incommensurate peaks for the superconducting samples with a maximum at $\sim 6 \mathrm{meV}$ in the energy spectrum. As doping increases, the maximum of the dynamic susceptibility $\chi^{\prime \prime}(\omega)$ decreases linearly with $T_{\mathrm{c}}$ and, finally, the low energy excitations become unobservable at $x=0.30$ coincidentally with the disappearance of bulk superconductivity. Magnetic excitation spectra in the intermediate energy range $(20<\omega<100 \mathrm{meV})$ are found to decrease monotonically with doping. These observations are discussed in terms of a phase separation of the system into a remnant magnetic region, which possibly consists of a stripe structure and supports the superconductivity, and a non-magnetic metallic region.

Keywords: High-T $T_{c}$ superconductivity, overdoped $\mathrm{La}_{2}{ }_{-} \mathrm{Sr}_{x} \mathrm{CuO} \mathrm{O}_{4}$, spin excitation
\end{abstract}

1.はじめに

銅酸化物における高温超伝導への磁性の寄与は, 多くの中性子散乱研究から示唆されてきた $[1,2]$. $\mathrm{La}_{2}-x \mathrm{Sr}_{x} \mathrm{CuO}_{4}$ (LSCO) 系では低エネルギー領域に おける格子非整合な磁気相関（静的相関も含めて） が超伝導に深く関係する [3-8]. その一方で, $\mathrm{YBa}_{2} \mathrm{Cu}_{3} \mathrm{O}_{6}+\delta(\mathrm{YBCO})$ 系では中間エネルギー領 域の $(\pi \pi)$ 近傍の磁気共鳴散乱が重要であるとす る報告が多くなされた [9-11]. また近年明らかとな った両者に共通の「砂時計型」と呼ばれる新奇な磁 気励起 [12-17]は，一見異なって見える両者の性質 を結びつけ，超伝導への磁性の寄与を統一的に理解 する足がかりとなっている.

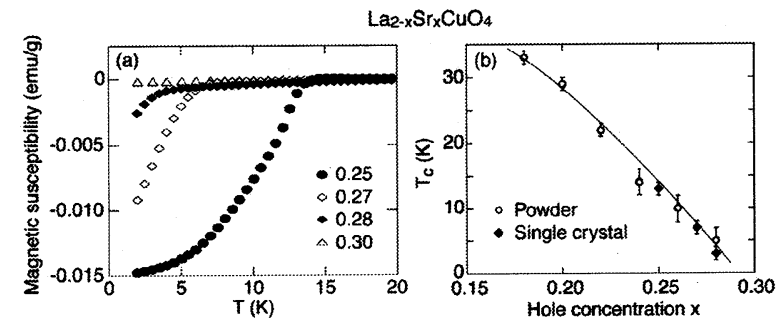

Fig.1 (a) Superconducting shielding signal measured in $10 \mathrm{Oe}$ after cooling in zero field. (b) Hole concentration dependence of $T_{c}$ (onset) for powder samples (circles) and single crystals (diamonds).
これらの中性子散乱研究は主に最適ドープ領域か らアンダードープ領域にかけて行われ，過剩ドープ 領域の研究はまだ多くなく $[6,18,19]$, YBCO 系に ついては過剩ドープ単結晶試料の作成が困難なため 皆無である. しかしながら, 超伝導の消滅に従って 変化する磁性を研究すれば，超伝導への寄与につい て重要な知見が得られるはずである.

本記事では筆者が LSCO 系過剩ドープ試料に関し て行った，広いエネルギー領域に渡る中性子散乱実 験をまとめ, 過剩ドープ領域での超伝導の消滅が反 強磁性磁気相関の消滅を伴って起こる様子を報告す る.

\section{2. 試料と中性子散乱}

実験に用いた単結晶試料は TSFZ 法により育成し た．酸素欠損をできるだけ少なくするため，3 気圧 の酸素中で $900{ }^{\circ} \mathrm{C}, 100$ 時間の熱処理を施した. 得 られた結晶のマイスナー磁化の測定結果を Fig. 1(a) に示す.これから各試料の超伝導転移温度 $T_{\mathrm{c}}$ (onset) は $14 \mathrm{~K}(x=0.25), 7 \mathrm{~K} \quad(x=0.27), 4.5 \mathrm{~K}(x=$ 0.28）と見積もられる. Fig. 1(b)に示すようにこれ らの值は粉末試料の結果と良くあっており，単結晶 の $\mathrm{Sr}$ 濃度が仕込み組成とほぼ一致していることが確 認できる. $x=0.30$ の試料では測定した最低温度の $2 \mathrm{~K}$ までバルクな超伝導は現れていない. $x=0.25,0.27,0.28,0.30$ の試料の低エネルギー 
領域 $(\omega<10 \mathrm{meV})$ の磁気励起は主に Chalk River Laboratory の C5 三軸分光器にて測定した。 各組成 あたり 2 本, 合計約 $2 \mathrm{cc}$ の単結晶を使用し， $a^{*}-b^{*}$ 面を散乱面とした。 反射中性子のエネルギーを 14.5 $\mathrm{meV}$ で固定し, 33'-48'-51'-120'のコリメーションを 用いた. $x=0.25,0.30$ の試料については高エネル ギー側 $(\omega>20 \mathrm{meV})$ の磁気励起をパルス中性子 源 ISIS に設置されている MAPS 飛行時間分光器で 測定した. 各組成につき 8 本 (合計約 $9.5 \mathrm{cc}$ ) の結 晶を使用し，入射中性子が $\mathrm{c}$ 軸に平行になるよう配

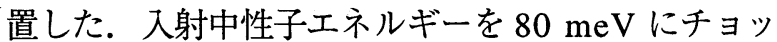
パー周波数を $300 \mathrm{~Hz}$ と，同じく $140 \mathrm{meV} に 400$ $\mathrm{Hz}$ の二つの条件で実験を行った。

使用した過剩ドープ試料はいずれも低温まで正方 晶 $(I 4 / \mathrm{mmm})$ で, $10 \mathrm{~K}$ での格子定数は $a=b=$ 3.76 A である。この場合， $a, b$ 軸は $\mathrm{Cu}-\mathrm{O}-\mathrm{Cu}$ 方向 $\left(\mathrm{CuO}_{2}\right.$ 正方格子の辺の方向 $)$ となる．本記事では正 方晶での表記を統一して用いることにする.

3. 低エネルギー $(\omega<10 \mathrm{meV})$ 磁気励起

三軸分光器による測定から，超伝導を示す全ての 試料 $(x=0.25,0.27,0.28)$ で，格子非整合な低 エネルギー磁気励起が観測された. $10 \mathrm{meV}$ 付近ま でのエネルギー依存性から, 全ての試料で $6 \mathrm{meV}$ 付 近に積分強度の極大を持つことがわかった. Fig.2(a) にそれらの試料の極大を持つエネルギー付近での磁 気励起を示す．右上図中の $\mathrm{A}$ 走査線上をスキャンし たものである.フォノン強度から評価した試料体積 の比は $x=0.25$ から順に 1:1.16:0.98:1.02 であり， 中性子散乱強度を直接比較して差し支えない。実線 は装置分解能を畳込んだ 2 次元ローレンツ関数での フィット結果である。この図から, 過㮃ドープ試料 の低エネルギー磁気励起は，格子非整合性 $\delta$ を 0.12 付近に一定に保ちながら，ホール濃度の増加に伴い

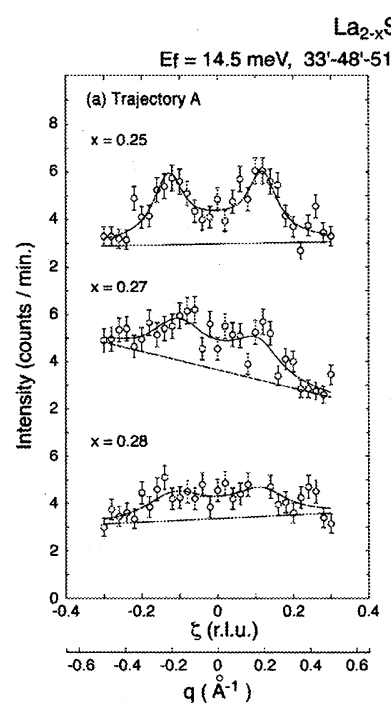

$\mathrm{a}_{2-x} \mathrm{Sr}_{x} \mathrm{CuO}_{4}$

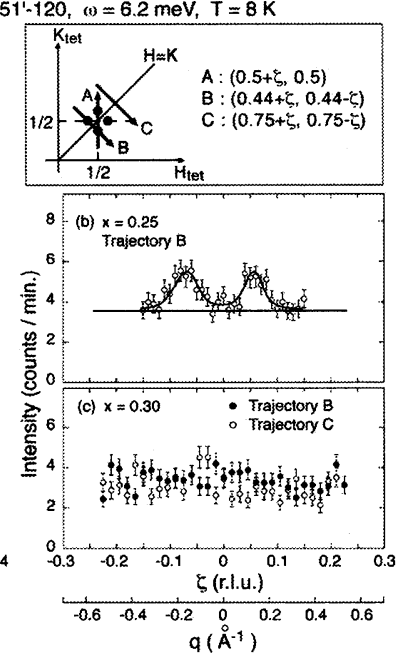

Fig.2 Incommensurate peak profiles for the overdoped samples. Scan trajectories are shown in the right-top figiure. These are measured at $8 \mathrm{~K}$ and energy transfer at $6.2 \mathrm{meV}(5.2 \mathrm{meV}$ for only $x=0.27)$ where the dynamic susceptibility $\chi^{\prime \prime}$ shows the maxumum.
減衰していくことがわかる.

さらにホール濃度を増加させ，超伝導が消滅した $x=0.30$ の試料のデータを Fig. 2(c)に示す. 格子非 整合ピークを通る B 走査線とバックグラウンド部分 を通る C 走査線に沿ったスキャンを示している，比 較として $x=0.25$ の試料の $\mathrm{B}$ 走査線スキャンを Fig. 2(b)に示す．明らかに， $x=0.25$ で見られる磁気散 乱が $x=0.30$ で消失している. $x=0.30$ の試料につ いては， $\mathrm{A}$ 走査線のスキャンや，他のエネルギーで のスキャンを行ったが, 磁気散乱を検出することが できず，超伝導の消失した $x=0.30$ 試料では $\omega<$ $10 \mathrm{meV}$ の低エネルギー磁気励起はほぼ消滅してい ると考えられる。

$6 \mathrm{meV}$ 付近の磁気散乱の極大值が超伝導とともに 減衰していく様子をより明らかにするため， $T_{\mathrm{c}}$ 依存 性を見てみることにする. Fig.2 で観測された磁気 散乱をフォノン強度で規格化し，ブリルアンゾーン で積分することで動的帯磁率の虚数部 $\chi "(\omega)$ を算出 し，比較を行った。 $\chi^{\prime \prime}(\omega)$ の温度依存性は $T_{\mathrm{c}}$ 付近で ブロードな極大を持つことから， $8 \mathrm{~K}$ で，6 $\mathrm{meV}$ 付 近の $\chi^{\prime \prime}(\omega)$ 值を用いることで，各組成の極大值を比 較できる. 得られた $\chi "(\omega)$ の極大值と $T_{\mathrm{c}}$ の関係を Fig.3に示す. 両者の間にはきれいな比例関係が成 り立ち, 低エネルギー磁気励起と超伝導の直接的相 関を示唆している.

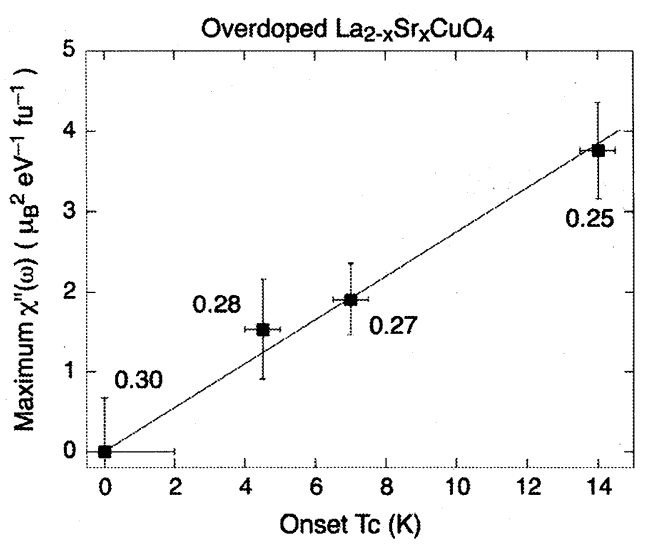

Fig. 3 Maximum $\chi^{\prime \prime}(\omega)$ at $8 \mathrm{~K}$ as a function of $T_{\mathrm{c}}$ (onset). The solid line is the result of a least square fit to a linear function.

4. 高エネルギー $(10<\omega<110 \mathrm{meV})$ 磁気励起 過㮃ドープ領域での低エネルギー磁気励起の消滅 を観測したが，では消滅した磁気散乱は高エネルギ 一ヘシフトしているのか，または全エネルギー領域 で磁気散乱が消滅するのかというのは重要な疑問で ある。これを解明するため, MAPS 飛行時間分光器 を用いて $x=0.25,0.30$ の試料の高エネルギー磁気 励起を調べた。

得られた過剰ドープ試料のデータにおいて, 高エ ネルギー領域の磁気散乱は非常に弱く, 同定するこ とは困難であった. Fig.4(a)-(c)に $x=0.25,0.30$ と， 
比較のため高エネルギー領域まで磁気散乱がよく観 測されている $\mathrm{La}_{1.875} \mathrm{Ba}_{0.125} \mathrm{CuO}_{4} \quad(\mathrm{LBCO} x=1 / 8)$ のデー夕（Xuら [20]による）を示す。高エネルギ 一側の散乱強度まで一つのカラースケールで見やす くするため, バナジウムの散乱強度で規格化した散 乱断面積にエネルギー変化量 $\omega$ をかけてある。ま た， $q$ 方向に磁気散乱が広がっている可能性を考慮 し, 中段右図の影の領域に相当する広い $q$ 領域の散 乱断面積を[110]方向に積分し，矢印で示された $(0.5+\zeta, 0.5-\xi)$ 上に射影した図となっている. よくよく見ると， LBCO では $\zeta=0 \quad(つ ま り ~(\pi \pi))$ 近傍にエネルギ方向へのびる磁気散乱強度が, フラ ットなフォノンの散乱強度に重なる形で見て取れる が, LSCO $x=0.25,0.30$ ではフォノン散乱のみが 目立っている。ここで，3つの試料でフォノンは大 きく変化しないが，磁気散乱は過剩ドープへ進むほ ど減衰していると仮定（実際この仮定が正しいこと は後に示す）し, LSCO $x=0.25$ と LBCO $x=1 / 8$ から LSCO $x=0.30$ のデー夕を差し引くことでフォ ノンの寄与を差し引くことを試みたのが Fig. 4(d), (e)であるＬBCO で見られる $(\pi \pi)$ 近傍に集約し
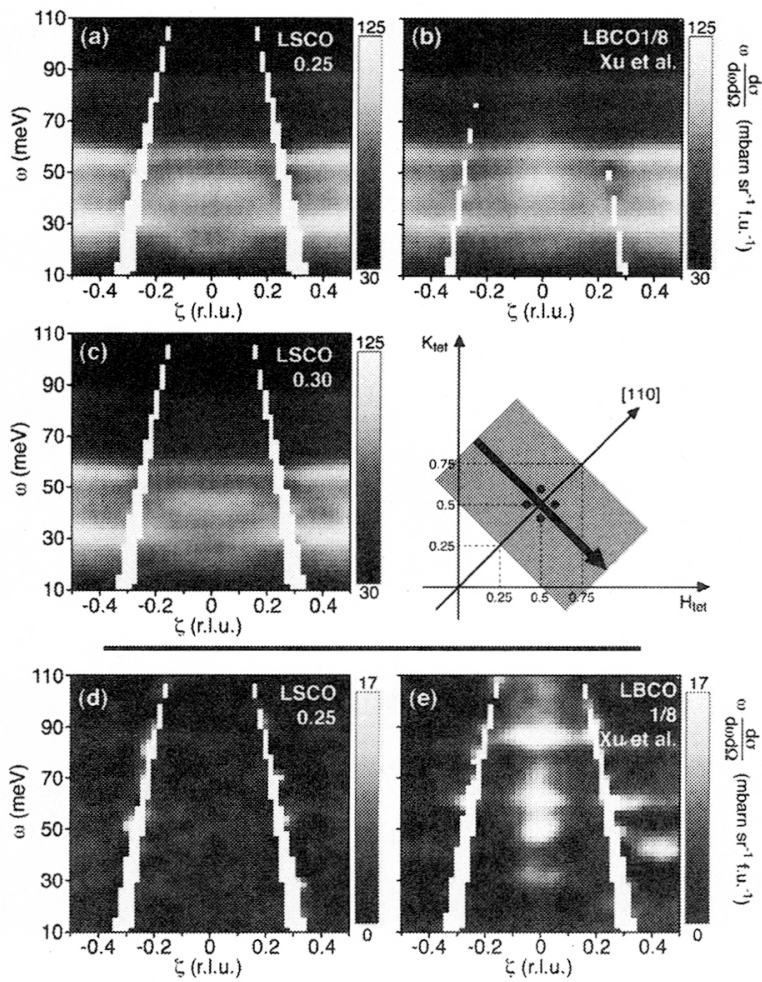

Fig.4 Contour plots of $\omega \times \mathrm{d} \sigma / \mathrm{d} \Omega \mathrm{d} \omega$ for (a) LSCO $x=0.25$, (b) LBCO $x=1 / 8$ (referred from Xu et al.[20]), and (c) LSCO $x=0.30$ measured with $E_{\mathrm{i}}=140 \mathrm{meV}$ at $10 \mathrm{~K}$. The plotted quantities are integrated for the shaded area in the right-middle figure along the [110] direction and projected on the $(0.5+\zeta, 0.5-\zeta)$ trajectory shown by the thick arrow. (d) and (e) show contour plots of differential intensities derived by subtracting data of LSCO $x=0.30$ from those of LSCO $x=0.25$ and those of LBCO $x=1 / 8$, respectively. The white regions arising from $\xi= \pm 0.3$ r.l.u. correspond to areas without detector coverage.
た磁気散乱はLSCO $x=0.25$ で大きく減少してお り，過剰ドープ領域での磁気散乱が非常に見えにく いものであることを示している。

このように， $\omega-q$ スライスでの強度マップでは磁 気散乱は同定しにくいが，一定のエネルギーにおけ る Fig.4 中の矢印方向へのカットプロファイルを調 ベると，有限の磁気散乱が見られた。それを Fig. 5 に示す.このデータは, Fig.4 と同様に広い範囲で の $q$ 積分を行い，かつエネルギー方向にも $\pm 5 \mathrm{meV}$ の範囲で積分した散乱断面積である。ここでも三つ の試料でフォノンは大きく違わないと考えれば，変 化しているのは磁気散乱であると考えられる。全体 のエネルギーを概観すると, $20 \mathrm{meV}$ 以上のエネル ギー領域においても，低エネルギー領域と同様，磁 気散乱が過剰ドープに従って系統的に減少して行く 様子が見て取れる.

これらのデータに対し次のような解析を行った。 まず，ここでプロットしている走査線上では Q の大 きさの変化が少ないことから，フォノンによるバッ クグラウンドは一つのスキャン上で一定であると仮 定した。ただし，35 meVのデー夕に限っては，

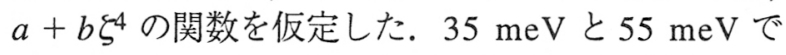
は $x=0.30$ のデータをバックグラウンドと取り, 80 $\mathrm{meV}$ と $100 \mathrm{meV}$ では一定值（図中の点線）をバッ クグラウンドとした. 以上で定めたバックグラウン ド上に現れる強度を磁気散乱とし，ガウシアン関数 でフィットして $q$ 積分を行い, 動的構造因子 $S(\omega)$ を

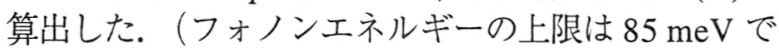
あり[21]，少なくとも $100 \mathrm{meV}$ のデータにおいて， バックグラウンド上の散乱は磁気的である.)

得られた $S(\omega)$ をFig.6に示す。比較のため,

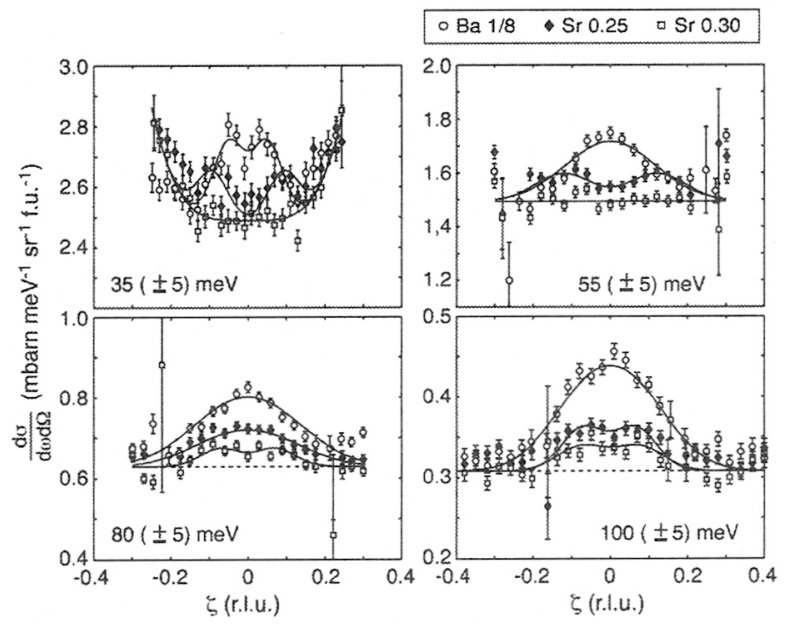

Fig.5 Intensity profiles cut along the trajectory in Fig.4 for LBCO $x=1 / 8$ (circles), LSCO $x=0.25$ (diamonds), and LSCO $x=0.30$ (sqares). These data are integrated in $\mathrm{q}$ in the same manner as the data in Fig. 4 and also integrated over an energy range of $\pm 5 \mathrm{meV}$. All data are taken with $E_{\mathrm{i}}=140 \mathrm{meV}$. Solid lines are results of fits to a double-Gaussian function. The fits for $x=$ 0.30 at $\omega=35$ and $55 \mathrm{meV}$ are set equal to backgound; in the bottom panels, backgound is shown by dashed lines. 


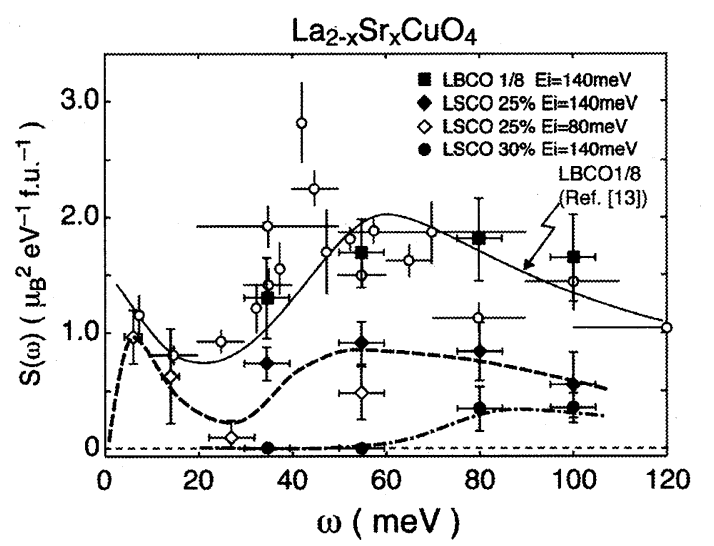

Fig.6 $Q$-integrated dynamic structure factor $S(\omega)$ which is derived from the wide- $q$ integrated profles for LBCO $x=1 / 8$ (squares), LSCO $x=0.25$ (diamonds; filled for $E_{\mathrm{i}}=140 \mathrm{meV}$, open for $E_{\mathrm{i}}=80 \mathrm{meV}$ ), and LSCO $x=$ 0.30 (filled circles) plotted over $S(\omega)$ for LBCO $x=$ 1/8 (open circles) from Ref. [2]. The solid lines following data of LSCO $x=0.25$ and 0.30 are guides to the eyes.

Tranquada ら [13]による LBCO $x=1 / 8$ のデータを (○) で示してある. 今回の方法で計算された LBCO のデータは(ロ) で示してあり, Tranquada らの結果 とよく一致している。 これは先に仮定したバックグ ラウンドが適切であることを示している． $x=0.25$ については $E_{\mathrm{i}}=140 \mathrm{meV}(\diamond)$ と $80 \mathrm{meV}(\diamond)$ のデ ータを, $x=0.30$ については $E_{\mathrm{i}}=140 \mathrm{meV}(\bigcirc) の$ データを示してある。 以上の結果から, 過剩ドープ 試料では低濃度領域試料と比較して， $\omega>20 \mathrm{meV}$ の磁気励起は減少しており, 低エネルギー領域の結 果と合わせて $60 \mathrm{meV}$ 以下の広いエネルギー領域の 磁気散乱が超伝導と同時に消滅することがわかった.

\section{5. 考察}

本研究において, LSCO の過剰ドープ領域の磁気 励起は広いエネルギー領域において，超伝導と共に 減衰して行くことが明らかとなった，低エネルギー 領域 $(\omega<10 \mathrm{meV})$ では $x \geq 0.25$ で $T_{\mathrm{c}}$ に比例し て減少し，さらに $20 \leq \omega \leq 60 \mathrm{meV}$ の中間エネル ギー領域においても，低濃度領域試料やVignolle ら [17]により報告された最適ドープ付近と比較しても 大きく磁気散乱が減少していた。 これと定性的に同 様の結果がLSCO $x=0.22$ において報告されている [19]. この節ではこの現象の物理的解釈を考察する.

\section{1. 相分離のモデル}

磁気散乱の消滅を説明する一つのモデルは, 磁気 散乱の起源が残留磁性にあり，その残留磁性を示す 領域が減少するという考え方, つまり残留磁性を担 う領域と非磁性の領域への相分離である. LSCOに おいて観測されている磁気散乱の格子非整合性 $\delta$ は $x=1 / 8$ 付近まで $x$ に比例して増加し, それ以上は ホール濃度が増加するにも関わらず $\delta$ は過剰ドープ 領域まで約 $1 / 8$ で一定である. ストライプモデル [22-24]で考えれば, $x=1 / 8$ 以上ではストライプ間
距離が変わらないことを示しており, 電荷ストライ プ内のホール濃度が異常に増加しているか, もしく は $\delta=1 / 8$ ストライプ相と電荷均一なフェルミ液体 相に相分離していると考えられる.ここで後者の相 分離のモデルが中性子散乱の結果に矛盾しないであ ろう. ストライプ相は反強磁性を担う領域であり, $x=1 / 8$ を境にその体積分率は減少していくことにな

る. 過利ドープ領域ではすでに体積分率は大きく減 少しているため, 磁気散乱の大きな減少を招くと考 えられる。

これまで中性子以外の研究において, $x \geq 0.20$ の 過㮃ドープ領域での超伝導体積分率の減少が報告さ れている [25-27]. ここで，上記ストライプ相の相 分離との整合性を考える上で注意しなければいけな いことは，反強磁性相関を保つストライプ相は超伝 導を誘起すると考えられるが，ストライプ相の体積 分率そのものが超伝導体積分率に等しい訳ではない という点である。ストライプ相の体積が著しく減少 した過剰ドープ領域では, ストライプ相が島状に存 在すると想像できるが，その島の間の距離が超伝導 コヒーレンス長を超えると超伝導体積分率が減少し 始めると考えられる. $x=0.20$ 付近から超伝導体積 分率が減少するのは、このクロスオーバーが起こっ ているためと考えられる。

\section{2. フェルミ面ネスティングモデル}

格子非整合な磁気非弾性ピークを説明する重要な モデルの一つに，フェルミ面のネスティングベクト ル方向へ電子がフェルミ面を超えて励起されること に起源を置くものがある [28-30]. またこのモデルを 用いて，最適ドープ付近の磁気励起に見られる砂時 計型の分散を再現する試みもなされている $[31,32]$. では過剩ドープの結果に適用できるだろうか?

光電子分光で観測されたフェルミ面形状のドープ 量依存性を見ると, $(\pi \pi)$ 方向の平らな部分（ネス ティングする部分）は過剒ドープにいくほど大きく なる [33]. また70 meV 付近までの電子の分散関係 はドープ依存性があまりない [34]. 以上のことを考 えるとネスティングによる寄与は過剰ドープ領域に 置いても $(\pi \pi)$ 近傍に顕著に現れるはずであるが, 中性子の結果では $60 \mathrm{meV}$ 付近までの磁気散乱は $x=0.30$ で完全に消えてしまっている.

ごく単純な可能性として，帯磁率の計算式に現れ る電子の交換相互作用 $J$ が非常に小さくなる場合が 考えられる.Jが小さくなると, 帯磁率は $q$ にブロ ードに広がった形となり,$x=0.25$ の試料で中間エ ネルギー領域の磁気散乱が $q$ に広がったように見え るのと定性的に合う。この場合，前節の相分離の場 合と異なり，磁気散乱は消滅する訳ではなく, $q$ 空 間に広がっていることになり， $x=0.30$ においても 有限のバックグラウンドが磁気散乱であるというこ とになる。 この可否を決定するのは偏極中性子散乱 しかないが，強度的に容易ではない. TOF では広い $q$ 空間を積分したデータが効率よく取れるので，こ れと偏極実験の組み合わせがJ-PARC で実現すると， 新たな結果が期待できそうである. 
6. おわりに

本記事で紹介した磁気散乱の消滅は LSCO に限っ た現象ではない可能性が高い.YBCO 系において も, $50 \mathrm{meV}$ までの積分散乱強度は酸素濃度の増加 と共に減少することが報告されている [35]. つまり ドープ量の増加に伴って磁気散乱が減少するのは LSCO 系と YBCO 系で類似の性質である. しかし， より共通の現象を知るためにも，LSCO 系以外の過 剩ドープ試料の研究が必要である.

今回の結果で興味深いのは, 砂時計型のくほみの 部分 (saddle point と呼ばれ YBCO 系では磁気共鳴 ピークが存在する部分）の励起が $x=0.30$ ではほほ 完全に消えており, $80 \mathrm{meV}$ 付近から磁気散乱が復 活する点である.この現象が，先に上げた相分離の モデルにせよ，フェルミ面ネスティングモデルにせ よ, 理論的に再現可能であるかは今後の重要な課題 である.

\section{謝辞}

本研究は山田和芳教授, I. Swainson 博士, J. M. Tranquada 博士，C. D. Frost 博士， R. J. Birgeneau 教授, H. Zhang 氏, H. K. Kim 氏の協力のもと行っ た. また G. Xu 博士には LBCO のデー夕を提供いた だいた. 故白根 元博士, W. J. L. Buyers 博士, S. A. Kivelson 教授，佐藤正俊教授，飯久保智博士には 非常に有益な議論をしていただいた．ISIS での実験 は日英中性子散乱研究協力事業の支援のもと行った.

\section{参考文献}

[1] M. A. Kastner, R. J. Birgeneau, G. Shirane, and Y. Endoh, Rev. Mod. Phys. 70, 897 (1998).

[2] R. J. Birgeneau, C. Stock, J. M. Tranquada, and K. Yamada, J. Phys. Soc. Jpn. 75, 111003 (2006).

[3] T. E. Mason, A. Schroder, G. Aeppli, H. A. Mook, and S. M. Hayden, Phys. Rev. Lett. 77, 1604 (1996).

[4] K. Yamada et al., Phys. Rev. B 57, 3686 (1998).

[5] J. M. Tranquada et al., Phys. Rev. B 69, 174507 (2004).

[6] S. Wakimoto et al., Phys. Rev. Lett. 92, 217004 (2004).

[7] S. Wakimoto et al., Phys, Rev. B 61, 3699 (2000).

[8] M. Fujita et al., Phys. Rev. B 65, 064505 (2002).

[9] H. F. Fong et al., Phys. Rev. B 61, 14773 (2000).

[10] P. Dai, H. A. Mook, R. D. Hunt, F. Dogan, Phys. Rev. B 63, 054525 (2001).

[11] C. Stock et al., Phys. Rev. B 69, 014502 (2004).

[12] S. M. Hayden, H. A. Mook, P. Dai, T. G. Perring, and F. Dogan, Nature 429, 531 (2004).
[13] J. M. Tranquada et al., Nature 429, 534 (2004).

[14] N. B. Christensen et al., Phys. Rev. Lett. 93, 147002 (2004).

[15] C. Stock et al., Phys. Rev. B 71, 024522 (2005).

[16] D. Reznik et al., Phys. Rev. Lett. 93, 147002 (2004).

[17] B.Vignolle et al., Nature Phys. 3, 163 (2007).

[18] S. Wakimoto et al., Phys. Rev. Lett. 98, 247003 (2007).

[19] O. J. Lipscombe et al., Phys Rev. Lett. 99, 067002 (2007).

[20] Guangyong Xu et al., Phys. Rev. B 76, 014508 (2007).

[21] L. Pintschovius, Phys. Status Solidi B 242, 30 (2005).

[22] S. A. Kivelson et al., Rev. Mod. Phys. 75, 1201 (2003).

[23] J. Zaanen et al., Philos. Mag. B 81, 1485 (2001).

[24] K. Machida, Physica C 158, 192 (1989).

[25] Y. Tanabe, T. Adachi, T. Noji, and Y. Koike, J. Phys. Soc. Jpn. 74, 2893 (2005).

[26] H. H. Wen et al., Europhys. Lett. 57, 260 (2002).

[27] Y. J. Uemura, Solid State Commun. 120, 347 (2001).

[28] N. Bulut and D. J. Scalapino, Phys. Rev. B 47, 3419 (2003).

[29] T. Dahm and L. Tewordt, Phys. Rev. Lett. 74, 793 (1995).

[30] Y.-J. Kao, Q. Si, and K. Levin, Phys. Rev. B 61, R11898 (2000).

[31] S. Iikubo, M. Ito, A. Kobayashi, M. Sato, and K. Kakurai, J. Phys. Soc. Jpn. 74, 275 (2005).

[32] M. R. Norman, Phys. Rev. B 75, 184514 (2007).

[33] T. Yoshida et al., Phys. Rev. B 74, 224510 (2006).

[34] X. J. Zhou et al., Nature 423, 398 (2003).

[35] P. Bourges, arXive: cond-mat/0009373. 